\title{
Clio e Melpomene: a correspondência entre Johan Huizinga e André Jolles sobre a escrita da História
}

Naiara Ribeiro*

Universidade Federal de Juiz de Fora, Juiz de Fora-MG, Brasil

\section{RESUMO}

Este artigo analisa a relação entre História e Literatura a partir da correspondência entre o historiador da cultura Johan Huizinga e o historiador da arte e da literatura André Jolles, em 1925, intitulada Clio e Melpomene. Amigos desde o final da década de 1890, Huizinga e Jolles compartilharam ao longo de suas carreiras um conjunto amplo de questóes em torno do problema da forma, colocando-a como conceito central da investigaçáo sobre o tema da escrita da História. Nessa correspondência, a definição de qual seriam os limites e aproximaçôes entre Clio e Melpomene ajuda a lançar luz tanto sobre a trajetória intelectual desses autores quanto sobre os debates persistentes acerca da elaboração do texto historiográfico.

Palavras-chave: Johan Huizinga; André Jolles; História; Literatura; forma.

\section{ABSTRACT}

This article analyses the relationship between History and Literature through the 1925 open correspondence between cultural historian Johan Huizinga, and art and literature historian André Jolles, titled Clio and Melpomene. Friends since the late 1890s, Huizinga and Jolles shared throughout their careers a wide range of thoughts on issues surrounding the problem of form, establishing it as a core concept in their investigations into historical writing. In this correspondence, the definition of limits and aproximations between Clio and Melpomene helps shed light on the intellectual trajectory of both authors, as well as on the ongoing debate about the writing of historiographical texts.

Keywords: Johan Huizinga; André Jolles; History; Literature; form.

DOI - http://dx.doi.org/10.1590/2237-101X017033014

* Professora no Departamento de História da UFJF. E-mail: naiaradamas@gmail.com. 
Em 1942, apenas três anos antes de sua morte na pequena cidade holandesa de De Steeg, o historiador da cultura Johan Huizinga (1872-1945) escreveu uma breve autobiografia em que narrava seu "caminho para História". Nesse curioso relato em que o leitor é conduzido através das experiências que marcaram sua decisão de abandonar os estudos como orientalista para abraçar a disciplina histórica como historiador da cultura, uma personagem se destaca, aquela do "talentoso e precioso André Jolles" (1874-1946). Huizinga se referia ao historiador da arte e da literatura, mais conhecido por sua importante obra no campo da morfologia literária, Formas simples, publicada em 1930. Esse livro ganhou notoriedade sobretudo nos anos 1970, quando foi reimpresso na França e incorporado ao campo dos estudos literários como parte de uma espécie de "pré-História" do Estruturalismo. ${ }^{1}$

Em sua autobiografia, Huizinga fazia questáo de afirmar que essa amizade, iniciada em 1896 e interrompida bruscamente em 1933 quando Jolles aderiu ao Partido nacional-socialista na Alemanha, "iria ter um grande papel em minha vida por mais de 35 anos". E dizia ainda que "poderia escrever um livro inteiro sobre a minha relação com Jolles, táo repleto o meu espírito está dele e - a despeito de tudo o que aconteceu — também o meu coração." 2 Para Jolles, uma espécie de artiste manqué no cenário intelectual holandês das primeiras décadas do século XX, a centralidade e o protagonismo de Huizinga em sua formação pessoal e intelectual foram reconhecidos em mais de uma ocasiáo, sendo que numa delas ele chegou a sugerir que uma vie parellele deveria ser escrita sobre a trajetória entrelaçada dos dois amigos. Uma amizade, portanto, que poderia ser vertida em livro, num registro que constitui para ambos o locus privilegiado para a elaboração de uma narrativa que organiza as linhas soltas, as convergências e as tensóes, de uma trajetória intelectual trilhada em paralelo e que girava em torno das possibilidades morfológicas da pesquisa histórico-cultural.

Nessa "vida paralela" de interesses compartilhados e desenvolvidos, por vezes, a quatro mãos, um momento que ajuda a compreender o entrelaçamento essencial da carreira de Jolles e Huizinga é a correspondência aberta sobre a escrita da História publicada na revista De Gids em 1925. Esse capítulo do diálogo entre Jolles e Huizinga é de importância fundamental na

\footnotetext{
${ }^{1}$ Robert Scholes em seu livro Structuralism in Literature, publicado nos anos 1970, foi um dos autores que indicou o pertencimento da obra de Jolles sobre as "formas simples", junto com a Morfologia do conto maravilhoso (1928), de Vladimir Propp, a uma corrente que denominou de "protoestruturalismo". Contudo, um conjunto significativo de autores tem sugerido a importância de reavaliar a inserção de Jolles no horizonte intelectual do Estruturalismo. Sobre isso, ver: CONTARINI, Silvia. Introduzione. In: JOLLES, André. I Travestimenti della letteratura. Saggi critici e teorici (1897-1932). Milão: Bruno Mondadori, 2003.

${ }^{2}$ HUIZINGA, Johan. My path to history. In: HUIZINGA, Johan. Dutch Civilization in the Seventeenth Century and Other Essays. Londres: Collins, 1968. p. 264. "This friendship was to play a large part in my life for more than 35 years"; "I could write a whole book on my relationship with Jolles, so full is my mind of him and — despite all that has happened — my heart as well". Essa e todas as subsequentes traduçóes no artigo são de minha autoria.
} 
medida em que não apenas lança uma luz reveladora sobre quais eram as questóes centrais que acompanhavam a formulação da História como morfologia de Huizinga nesses anos, mas também por ser um fragmento crucial da reflexão que levaria Jolles a publicar sua grande obra Formas simples em 1930. A ocasião desse diálogo sobre Clio e Melpomene foi um artigo escrito por Huizinga sobre a peça de teatro do dramaturgo irlandês Bernard Shaw, Saint Joan (1923). Ao responder às questôes levantadas nesse artigo sobre os limites das formas artísticas para se apropriarem de determinados temas históricos, Jolles iniciava um debate sobre a escrita da História e seu pertencimento ao campo da literatura. O que estava em jogo nessa correspondência era a relação entre a História e a poesia, tocando no problema mais amplo de fronteiras, cruzamentos e tensões entre a forma histórica e a forma literária.

\section{Clio versus Melpomene}

A ocasião desse diálogo foi um artigo escrito por Huizinga, também publicado em De Gids alguns meses antes de Clio e Melpomene em 1925, sobre a peça de teatro de Bernard Shaw, Saint Joan, representada pela primeira vez em 1923, em Nova York, e publicada em 1924 com um prefácio do dramaturgo irlandês. ${ }^{3} \mathrm{O}$ epicentro da interrogação de Huizinga, caracterizada por ele como "notas marginais de um historiador", era refletir sobre qual seria o motivo do sucesso da peça shawniana que, naquele momento, estava "viajando pelo mundo", atraindo "pessoas (não apenas por causa de Shaw), movendo-as, afetando-as - e as edificando". ${ }^{4}$ Seria esse sucesso o resultado do talento do dramaturgo irlandês ou emanaria do próprio tema da peça, a história da Donzela de Orleáns? Essa pergunta deveria ser respondida levando em conta o escopo e os desafios envolvidos na tarefa que Shaw havia se colocado, uma tarefa que, segundo Huizinga, era a "mais alta (...) que o espírito humano conseguiu, poucas vezes, realizar: a criação da tragédia a partir da história". ${ }^{5}$ O que estava em jogo nessas "notas" era a questão da transposição da história, "do que realmente aconteceu”, para o domínio poético da forma trágica, abrindo-se, assim, para o problema mais amplo das fronteiras, cruzamentos e tensóes entre a forma histórica e a forma artística.

Apesar de concordar com Shaw sobre os perigos da idealização romântica de Joana d'Arc, discutidos largamente no prefácio de 1924, Huizinga questionava-se em que medida a opção por uma representação "realista" da Donzela, que pretensamente o tornaria imune

\footnotetext{
${ }^{3}$ Johan Huizinga, como sugerido pelo seu próprio artigo, esteve presente em duas encenaçóes da peça Saint Joan de Bernard Shaw em 1925 — no Regend Theather em Londres e em Amsterdam na produção do grupo teatral Veerenigdtooneel.

${ }^{4}$ HUIZINGA, Johan. Bernard Shaw's Saint. In: Men and Ideas: History, the Middle Ages, the Renaissance. Nova York: Meridian Books, Inc., 1959. p. 208. "historian's marginal notes"; "the play is traveling through the world, and it attracts people (not only because it is Shaw), moves and affects them - and uplifts them". ${ }^{5}$ Ibidem, p. 208. "the highest task the human mind has succeeded, a few times, in accomplishing: the creation of tragedy from history".
} 
à tentação do "melodrama", teria contribuído ou não com o efeito dramático do espetáculo. Para o historiador, embora Shaw acreditasse ter "capturado a essência histórica dos eventos" e oferecido a seu público "tudo o que se precisa saber sobre Joana d'Arc", ${ }^{6}$ ele não teria sido capaz de cumprir um requisito fundamental de qualquer relato sobre a vida da heroína de Orleáns. Joana d'Arc estaria muito firmemente ancorada na história francesa do século $\mathrm{XV}$ "para ser capaz de servir como um personagem dramático atemporal como Phaedra ou Alcestis". O drama de Santa Joana deveria "nos transportar para Idade Média como a vemos". Esse não seria o caso na peça de Shaw: o arcebispo de Reims soaria "notavelmente anglicano", o delfim "é demasiadamente um Eton boy mimado" e, por fim, a peça é "muito shawniana para parecer medieval". ${ }^{8}$

Nessa crítica, não se tratava simplesmente de apontar para uma falta de empatia de Shaw pelo período medieval, uma inabilidade de se identificar com o século de Joana d'Arc — que era também o século abordado por Huizinga em seu livro O outono da Idade Média (1919) —, ou de avaliar a peça a partir de um ponto de vista factual e escolar. Em sua consideração sobre a relação entre história e drama, havia uma clara percepção de que o drama histórico, na condição de artefato artístico, opera segundo um regime de verdade distinto daquele do gênero historiográfico. "É evidente que nenhuma culpa deve ser atribuída ao dramaturgo por sua abreviação deliberada da realidade da história" . O problema central em torno dos limites do drama shawniano referia-se antes a uma deficiência dramática considerada de um "tipo muito mais sério", mas que estava inseparavelmente ligada à questão da representação histórica em Saint Joan. Essa deficiência seria decorrente do caráter excessivamente moderno da "prosa" da peça — não apenas na forma, mas também na concepção — , aparente na ausência das "qualidades poéticas do trágico"10 capaz de "lançar uma luz sobre a diferença

${ }^{6}$ Ibidem, p. 209. Citaçóes extraídas por Huizinga do prefácio de Saint Joan. Cf. SHAW, Bernard. Saint Joan: a chronicle play in six scenes and an epilogue. Londres: London GroupLimited, 1970.

${ }^{7}$ Ibidem, p. 211. "to be able to serve as a timeless dramatic personage such as Phaedra or Alcestis"; "must transport us to the Middle Ages as we see them".

${ }^{8}$ Idem. "the archbishop of Reims strikes one as remarkably Anglican"; "the dauphin is all too much the spoiled Eton boy"; "is all too Shavian to seem medieval".

${ }^{9}$ Ibidem, p. 210. "It goes without saying that no blame is due the dramatist for his deliberate abbreviation of the reality of history".

${ }^{10}$ Apesar de não fazer uma referência explícita ao gênero trágico estabelecido na Poética, Huizinga parece operar aqui com as categorias estabelecidas pela tradição aristotélica quando enfatizava a questão da elocução para avaliar o efeito dramático da peça e a eficácia de sua composição poética. Como afirma Stephen Halliwell na introdução da tradução inglesa do tratado aristotélico, o objetivo da Poética poderia ser visto como uma demarcação do escopo ideal da tragédia. "Essa demarcação é inicialmente materializada na definição do gênero, que acentua dois aspectos peculiares à tragédia: a estrutura de uma ação 'elevada' e o despertar de "compaixão e temor". O primeiro desses aspectos (...) representa em parte uma gravidade genérica de tom, mas também (ou ao mesmo tempo) uma questão de intensidade ética. 'Elevada', spoudaios, é o termo usado para denotar o nível típico da caracterização encontrada na tragédia e no épico; o tema do sério em contraposição à poesia cômica; a universalidade quasi-filosófica da poesia em oposição à particularidade da história." HALLIWELL, Stephen. Introduction. In: ARISTOTLE. Poetics. Cambridge: Harvard University Press, 1955, p. 13. 
entre as épocas sem revelar isso completamente" e transportar "as nossas mentes a uma atmosfera onde todas as paixóes e emoçóes adquirem uma potência maior, onde cada palavra deve ir mais fundo e soar mais solene do que na vida ordinária”. ${ }^{11}$

Embora avaliasse Saint Joan como uma "dramatização insatisfatória de seu nobre tema”, o que tornaria a peça shawniana bem-sucedida seria o próprio tema histórico, a vida e a morte de Joana D’Arc. Era sua impressão que a peça produzia o seu efeito mais profundo "quase além da própria atividade de Shaw, como se o grande tema tivesse meramente passado através dele para se manifestar diretamente em toda a sua verdade fascinante e pureza imaculada" ${ }^{12}$ Ao contrário de Hamlet, em que o elemento trágico seria o produto da criação de Shakespeare, de sua intencionalidade artística, o poderoso "efeito trágico" da peça adviria da história mesma de sua protagonista e não das habilidades representacionais do dramaturgo - ou ainda, quase a despeito delas. Nesse sentido, as afeiçóes associadas às convençóes da forma trágica, a compaixão e o temor — por meio das quais se realizaria a finalidade da tragédia, a catarse - seriam despertadas, nos espectadores, pela "grandeza da Santa, cujo servo ele [Shaw] era aqui". 13

A figura heroica da Donzela de Orléans seria um desses temas históricos cuja imagem "clara e precisa" que emergia da tradição não poderia ser apreendida pela forma literária de Voltaire a Shaw, todos teriam fracassado. Nesses casos, uma espécie de hiper-realidade - Joana d'Arc seria, para o historiador holandês, "demasiadamente real" [zer was te reëel $]^{14}$ - impediria a transposição satisfatória da história para o domínio poético. Essa impossibilidade estaria ancorada na própria natureza do empreendimento poético que constituiria a relação entre a história "factual” e as formas artísticas, em especial o drama histórico. Como afirmava Huizinga, a representação teatral de um acontecimento factual admitiria certas imprecisóes e "licenças" em função da produção do efeito dramático, colocando a questão da autenticidade num plano diverso daquele de uma adequação ao domínio da realidade, do "aconteceu assim", que traz como marca distintiva o pacto entre autor e audiência em torno da suspensão das normas da verdade literal. ${ }^{15}$ A tragédia, segundo ele, "pode ser qualquer coisa menos puramente natural e realista". ${ }^{16}$

\footnotetext{
${ }^{11}$ HUIZINGA, Johan. Bernard Shaw's Saint, op. cit., p. 212. "which casts a light on the difference in times without revealing it completely"; "our minds into a sphere where each emotion and passion has acquired a higher potential, each words affects more deeply and resonates more fully than in everyday life".

${ }^{12}$ Ibidem, p. 213. "almost beyond Shaw's own activity, as if the great theme has merely passed through him to manifest itself directly in all its gripping truth and spotless purity".

${ }^{13}$ Idem. "the greatness of the saint whose servant he there was".

${ }^{14}$ Ibidem, p. 221. "she was too real". Algumas correçóes e precisóes conceituais referentes à tradução dos textos de Huizinga serão indicadas, ao longo do artigo, pelos termos originais em holandês entre colchetes. As obras de Huizinga em holandês estão disponíveis em: <http://www.dbnl.org/auteurs/auteur.php?id=huiz003>. Acesso em: maio 2016.

${ }^{15}$ HALliWELL, Stephen. The Asthetics of Mimesis: Ancient Texts and Modern Problems. Princeton: Princeton University Press, 2002, p. 166.

${ }^{16}$ HUIZINGA, Johan. Bernard Shaw's Saint, op. cit., p. 212. "Tragedy may be anything but sheerly natural and realistic."
} 
Mas se Joana d'Arc não poderia ser encontrada nas obras de literatura e no teatro, onde seria possível buscá-la para entrar em contato com sua história e seu tempo? "São nos escritos que querem oferecer puramente a história [die zuiver de historie] que o leitor, incluindo o público mais amplo, busca a Donzela de Orleáns". E acrescentava que "as melhores páginas que se lê sobre Joana d'Arc e sua vida" seriam encontradas em Jules Michelet. ${ }^{17}$ A presença do historiador francês ${ }^{18}$ pode ser reveladora na medida em que seu trabalho sobre a História da França, no qual figurava a heroína francesa, acenava igualmente para a distinção entre História e Literatura, opondo a "arte propriamente literária”, que retrata um acontecimento histórico com as tintas do milagre e do fabuloso, e o "método histórico", capaz de restituir a "sublimidade" dessa personagem ao domínio "natural" dos acontecimentos. ${ }^{19}$ No prefácio à edição de 1868 de Histoire de France, Michelet advertia contra a tentação de "romancear" a Donzela:

Qual legenda mais bela do que essa história incontestável? No entanto, é necessário evitar convertê-la em uma legenda; nós devemos piedosamente conservar nela todos os traços, mesmo os mais humanos, respeitando a sua realidade comovente e terrível... Que o espírito romanesco a toque, se ele ousar; a poesia nunca o fará. O que ela saberia acrescentar?20

Assim, apenas o relato capaz de evocar a "realidade comovente e terrível” de Joana d'Arc, de fazer "ressuscitar" o passado em cores e imagens — para usar um termo micheletiano empregado amiúde por Huizinga em sua obra — através de uma imaginação que se dirige para o real, e a este se condiciona, poderia capturar o aspecto sublime dessa personagem. Para o historiador holandês, assim como para Michelet, não se tratava, porém, da ambição de deixar o passado falar por si mesmo, ou de "dizer o real", mas da composição de imagens animadas de vidas pretéritas, empregando um expediente narrativo "que transfigura o passado no campo da arte", ${ }^{21}$ evocando-o em suas próprias condiçôes e sentidos, isto é, em seu caráter contingente e particular. Como afirmava em sua aula inaugural $O$ elemento estético da representação histórica (1905), na qual defendia a tarefa da História em termos de uma

\footnotetext{
${ }^{17}$ Ibidem, p. 216. "It is in the books that attempt to give an accurate account of the history that the reader including the general reader — goes searching for the Maid of Orleáns"; "the great writings one reads about Joan of Arc and her life."

${ }^{18}$ Sobre a admiração de Huizinga pela obra de Jules Michelet, ver: VOOGD, Christophe Nicolaas. Le miroir de la France: Johan Huizinga et les historiens français. Tese (Doutorado) - Universidade de Leiden, 2013, p. 136-148.

${ }^{19}$ MICHELET, Jules. Préface de 1869. In: MICHELET, Jules. Ouvres Complètes. Histoire de France, t. I. Paris: Flammarion, 1893, p. XXXV-XXXVI.

${ }^{20}$ Ibidem, p. 157. "Quelle legende plus belle que cette incontestable histoire? Mais il faut se garder bien d'en faire une legende; on doit en conserver pieusement tout les traits, même les plus humains, en respecter la réalité touchant et terrible...Que l'esprit romanesque y touche, s'il ose; la poésie ne le fera jamais. Eh! Que saurait-elle ajouter?"

${ }^{21}$ PETITIER, Paule. Michelet e a História-ressurreição. Olho d'água, v. 5, n. 2, p. 63-78, 2013, p. 71.
} 
"revivência" do passado, somente quando a imaginação fosse estimulada expressamente "até que a mesma, ultrapassando o limite da fantasia histórica [historische fantasie], se transforma em fantasia artística, pode acontecer que elementos capazes de transformar a imagem em detrimento da verdade histórica se agreguem à representação". ${ }^{22}$

A consideração sobre o fracasso das formas literárias no caso de Joana d'Arc seria um indicativo das potencialidades únicas e distintivas da forma histórica em seu compromisso epistemológico, e ético, de "oferecer puramente a história" — em oposição, portanto, a um emolduramento ficcional do mundo histórico fundado na suspensão da "verdade literal". Esse relato histórico "puro" seria, segundo Huizinga, a forma mais adequada, e potencialmente mais efetiva, para a representação da vida da Donzela, para arrebatar os leitores, transportando-os por meio de uma prosa que recusava a fabulação, mas se constituía a partir de uma imaginação mobilizada para "conjurar" o drama "real" do passado. Se havia temas que prosperavam na forma épica, como a guerra de Troia de Homero, e outros na forma do drama, haveria ainda aqueles "cujo caráter está contido mais íntima e indissoluvelmente na forma histórica mesma, alguns nos quais as mais altas [hoogste] emoçóes do trágico, a compaixão [medelijden] e a catarse, estão vinculadas ao relato histórico [geschiedverhaal] enquanto tal". ${ }^{23}$ Michelet parecia indicar algo que se tornaria uma verdade também para Huizinga: quando a história era tão pungente, a poesia, em seu sentido como fabulação, deveria se calar. "J'ai dit tout simplement les choses", afirmava o historiador francês sobre seu relato da vida da Donzela. ${ }^{24}$

Essa singularidade da forma histórica fazia Huizinga afirmar na conclusão de seu artigo que, em algumas ocasióes ao longo dos séculos, a musa da História Clio teria a precedência sobre Melpomene, musa do drama, invertendo assim a hierarquia clássica estabelecida na Poética, que teve uma longa e complexa fortuna na tradição ocidental. Se para Aristóteles “a poesia é mais filosófica e mais nobre que a história” porque "a poesia se refere, de preferência, ao universal; a história, ao particular”, ${ }^{25}$ para Huizinga, em certos casos, a história poderia chegar a rivalizar com a universalidade da poesia, sem deixar, porém, de ser particular, e na concretude preservada na forma histórica, mais apta a atualizar os efeitos trágicos do temor e da compaixão por meio dos quais se realizava a catarse. Na Poética, Aristóteles chamava de particular, em oposição ao universal da poesia — fundado nos critérios da probabilidade e da necessidade — , "o que Alcebíades fez ou o que ele sofreu", sendo esta a marca da estatura inferior do gênero histórico e da ausência, ou o menor grau, de sua universalidade em relação

\footnotetext{
${ }^{22}$ HUIZINGA, Johan. El elemento estético de las representaciones históricas. Prismas: Revista de Historia Intelectual, n. 9, p. 91-107, 2005, p. 106.

${ }^{23}$ HUIZINGA, Johan. Bernard Shaw's Saint, op. cit., p. 216. "There are also some whose character lies most intimately and indissolubly contained in the historical form itself, some which the most sublime emotions of the tragic the fellow suffering and the catharsis - are bound to the historical account as such".

${ }^{24}$ MICHELET, Jules. Préface, op. cit., p. XXXVI. "Eu simplesmente disse as coisas."

${ }^{25}$ ARISTÓTELES. Poética. São Paulo: Editora 34, 2015, p. 97.
} 
à arte poética. Huizinga parecia retomar essas palavras para afirmar, na direção contrária, que o que Joana d'Arc fez ou sofreu, a sua "bela ação", para usar outro termo aristotélico, seria o espaço privilegiado para despertar as emoções trágicas, numa aposta que, ao mesmo tempo, reforçava e ressignificava a oposição aristotélica entre história e poesia.

\section{Clio e Melpomene, a história no horizonte das formas simples}

$\mathrm{O}$ artigo de Huizinga sobre Bernard Shaw provocaria a reação quase imediata de Jolles que, em sua resposta, uma carta aberta publicada na revista De Gids em 1925, escolhia se concentrar sobre o aspecto formal da escrita da História para tentar descobrir "se Clio não era, em si mesma, uma espécie de Melpômene" — isto é, se a história não seria uma espécie de "poesia" ${ }^{26}$ Em termos polêmicos, Jolles se interrogava em que medida o "relato histórico" [historie] não seria, em si mesmo, uma variante da "forma literária" [letterkundige vorm], dissolvendo, desse modo, o contraste que havia sustentado o argumento de Huizinga sobre a superioridade da narrativa histórica em relação à narrativa literária no caso da Donzela de Orleáns. Sugerindo uma aproximação fundamental entre a escrita da história e a literatura, Jolles pretendia refletir "até que ponto a história [histoire], na condição de 'representação do verdadeiro', assume uma forma que corresponde ao que nós chamamos em literatura de 'forma simples". ${ }^{27}$

A reflexão sobre a literatura a partir do conceito de forma simples estava no horizonte dos trabalhos que Jolles vinha desenvolvendo nos anos 1920. Em um conjunto de textos publicados na revista holandesa De Gids, onde Huizinga atuava como editor, sobre literatura medieval — depois reunidos no livro Intuição e forma (1923) — e no artigo "O conto na literatura ocidental moderna", ${ }^{28}$ já era possível perceber o esboço de um projeto que ganharia contornos definitivos em sua obra de síntese, Formas simples, publicada em 1930: o de investigar a "poesia" não em sua "fixação artística definitiva” como obra literária acabada, "mas onde ela ganha as suas raízes, isto é, na linguagem” por meio de uma pesquisa morfológica que deveria traçar "o itinerário que vai da linguagem à literatura" ${ }^{29}$ Nesse percurso, as for-

\footnotetext{
${ }^{26}$ JOLLES, André; HUIZINGA, Johan. Clio et Melpomène. Poetique, n. 100, p. 487-505, 1994, p. 502. Melpomene, musa inspiradora do drama, assume na carta de Jolles o sentido mais amplo de "poesia". "si Clio n'est pas en soi une sorte de Melpomène”.

${ }^{27}$ Ibidem, p. 497. “jusqu'à quel point l'histoire, em tant que representation du vrai, prend une forme que correspond à ce qu'on apelle en littérature une 'forme simple."

${ }^{28}$ Esse artigo e outros textos de Jolles desse período foram reunidos na obra: JOLLES, André. I Travestimenti della letteratura. Saggi critici e teorici (1897-1932). Milão: Bruno Mondadori, 2003.

${ }^{29}$ A proposta de Jolles em sua ciência morfológica era uma inversão do caminho de pesquisa que ele acreditava ser normalmente trilhado pela história da literatura, que pouca ou quase nenhuma atenção havia dedicado ao estudo das formas simples, deixando-as a cargo de disciplinas como a etnologia e o folclore. Essa inversão refletia o fato de que as formas simples escapariam à estilística, à retórica e à poética, só podendo ser apreendidas em um percurso que, partindo das formas simples atualizadas, revelaria as "unidades elementares"
} 
mas simples — definidas como "unidades primordiais" que funcionavam como a priori expressivos da pré-compreensão da experiência humana ${ }^{30}$ — garantiriam o acesso ao impulso comunicativo de atribuição de valor e sentido à realidade num "estado de agregação pré-literário” através de um movimento que, partindo de suas atualizações em produções textuais, chegaria até um conjunto limitado de "disposiçōes de espírito" que criam formas nas quais se "produz, cria e significa os fatos vividos" ${ }^{31}$ A cada "disposição do espírito", compartilhada potencialmente por todos os homens e atualizada de modo diverso segundo a cultura em que surgem, corresponderia uma das nove formas simples analisadas pela morfologia jollesiana: mito (episteme), saga (parentesco), legenda (imitação), advinha (gnose), ditado (experiência), caso (norma), memorável (concreto), conto (moralidade) e chiste (dissolução). ${ }^{32}$ Em Clio e Melpomene, este insight sobre as "formas simples" como "moldura" que organizava a experiência na e através da linguagem serviria de enquadramento teórico para investigar a dimensão formal da escrita da história como espaço textual em que a "disposição espiritual" para apreender e interpretar o domínio da factualidade se atualizava segundo as convenções da forma simples do memorável.

A réplica de Jolles apresentava-se como um prolongamento de um tema mencionado de modo breve em A santa de Bernard Shaw. Ao se questionar sobre como seria possível "experimentar" o passado como contraste em relação ao presente, Huizinga havia empregado o termo "sentido histórico" [historische zintuig] para sugerir a existência de uma habilidade "sensória" — ou "órgão do conhecimento histórico" — capaz de oferecer o passado como história. ${ }^{33}$ Jolles se propunha a investigar qual seria a função do "sentido histórico" - como age e ao que obedece - tomando como ponto de partida a breve descrição que Huizinga havia dado em seu artigo sobre a composição da imagem de Joana d'Arc, quando afirmava que a imagem histórica não se formava na mente do historiador "no plano de definiçóes psicológicas", mas nascia "sem nenhuma função lógica consciente, como a visão de algo que não se podia ver antes ou se podia ver apenas vagamente" a partir "dos dados arbitrários e mais ou menos circunstanciais que a tradição preservou" ${ }^{34}$ A convicção de que a imagem seria autêntica, e a tradição confiável, teria origem num sentimento, "difícil de descrever,

em que a linguagem se cristaliza para se "apoderar" da realidade, permitindo "explicar a forma do fenômeno literário" ali onde a própria linguagem, na condição de um trabalho de fabricação, produção e significação, cria o ato poético "sem a intervenção (...) de um poeta". JOLLES, André. Formas simples. São Paulo: Cultrix, 1976, p. 19-20.

${ }^{30}$ PASERO, Nicollò. Del buon uso della morfologia. Glosse a Warburg, Curtius e Jolles, Moderna, v. VI, n. 2, p. 35-38, 2004. p. 37.

${ }^{31}$ JOLLES, André. Formas simples, op. cit., p. 48.

${ }^{32}$ LANGBEHN, Regula R. La Teoria de las “formas simples” de André Jolles (1874-1946): una reconsideración. Hispanic Research Journal, v. 3, n. 3, p. 243-260, 2002. p. 245.

${ }^{33}$ HUIZINGA, Johan. Bernard Shaw's Saint, op. cit., p. 212.

${ }^{34}$ Ibidem, p. 225. "It arises seemingly without any consciously logical function"; "the arbitrary and more or less circumstantial data that the tradition has preserved"; "that though the various data are disconnected in themselves, they harmonize, they fit together." 
de que, apesar dos vários dados estarem desconectados entre si, eles se harmonizam e se correspondem [klopplen]". ${ }^{35}$ A descrição da imagem histórica em termos de "correspondência" acenaria, segundo Jolles, para uma concepção do "sentido histórico" que poderia ser interpretada pelo emprego, por parte do historiador, do repertório das formas simples, o que permitiria recolocar o "problema da apreensão [vatten] da realidade histórica" da perspectiva da linguagem. "Em qual forma literária — ou formas — se manifesta [vertoont] a história [historie]?”36 Já de saída, a pergunta que orientava sua réplica indicava a hipótese de que a realidade seria apreendida e se manifestaria enquanto história como o resultado de um processo mediado pela composição de uma forma literária.

Embora não mencione em sua carta aberta, ao partir do tema da formação da imagem histórica, Jolles retomava uma questão que Huizinga havia abordado em sua aula inaugural de 1905. Em uma crítica contundente ao "realismo histórico", Huizinga optava por abordar o ofício do historiador a partir do conceito de representação por meio do qual indicava o processo de transformação graças ao qual "a imagem teórica a que chamamos História é formada pelo material da realidade imediata e já vivida". ${ }^{37}$ Nessa "atividade mental", o historiador deveria recorrer a "funçôes psíquicas" que estariam muito além de "uma associaçáo de ideias puramente lógicas", o que assinalaria a "presença de um elemento imaginativo", uma "disposiçáo de espírito" para estabelecer o significado e a relação entre os fatos compartilhada, segundo ele, pelo historiador e pelo poeta no seu impulso em tornar a realidade inteligível através da construção de imagens. Essa disposição permitiria ao historiador "extrair e interpretar da multiplicidade disso que é dado aquilo que pertence essencialmente a um complexo de fenômenos históricos, aquilo que torna possível a realizaçấo desse complexo", transpondo-o em "imagens mentais" [denkbeeld] que deveriam preservar uma relação autêntica e "vivaz" [aanschouwelijk] com o passado. ${ }^{38}$

Esse impulso do historiador em direção à constituição de um complexo a partir de fragmentos da tradição, isto é, de uma imagem, seria, para Jolles, intrinsecamente semelhante ao processo de atualizaçáo da forma simples do memorável numa composição literária. Tal como na imagem histórica descrita por Huizinga, a "disposiçấo mental" para apreender a realidade "efetiva", factual, se realizaria através da construção de uma totalidade, uma forma [Gestalt] na qual a "multiplicidade e a diversidade do ser e do acontecimento" se cristaliza "para assumir uma certa configuração", tornando "os acontecimento imagináveis". ${ }^{39}$ Essa

\footnotetext{
${ }^{35}$ Ibidem, p. 212.

${ }^{36}$ HUIZINGA, Johan; JOLLES, André. Clio et Melpomène, op. cit., p. 493. "dans quelle forme littéraire — ou forms — se presente l'histoire?"

${ }^{37}$ HUIZINGA, Johan, El elemento estético de las representaciones históricas, op. cit., p. 97.

${ }^{38}$ Ibidem, p. 104.

${ }^{39}$ Em sua obra de 1930, Jolles define as formas simples nos seguintes termos: "Sempre que uma disposição mental leva da multiplicidade e a diversidade do ser e dos acontecimentos a se cristalizarem para assumir uma certa configuração; sempre que tal diversidade, apreendida pela linguagem em seus elementos primordiais e indivisíveis e convertida em produção linguística, possa ao mesmo tempo querer dizer e significar o ser e o
} 
configuração realizada de modo espontâneo pelo labor da própria linguagem, gerando o ato poético criador das formas simples, estaria na origem da forma literária do memorável. "Estamos na presença de uma disposição mental que trabalha sobre o concreto. (...) Veremos (...) como essa disposiçáo mental está de acordo com uma cadeia de pensamentos precisos que cria uma forma". 40

O emprego do memorável ficaria evidente no modo como os historiadores organizavam, selecionando e interpretando, os dados da tradição, de modo a reportá-los no relato histórico. "Esses dados são - para repetir as suas palavras — 'sempre arbitrários, e mais ou menos fortuitos', incoerentes" - afirmava Jolles, citando o artigo de Huizinga sobre Bernard Shaw. ${ }^{41}$ Para arranjá-los numa relação coerente, o historiador comporia um "complexo", uma forma literária "onde os detalhes (...) têm uma significação, são relacionados uns aos outros e são preenchidos por um significado de conjunto", ${ }^{42}$ replicando o movimento da multiplicidade para unidade que Huizinga abordava na formação da imagem histórica, mas agora em termos de uma composição literária. $\mathrm{O}$ modo como se dava a incorporação dos detalhes históricos na formaçáo dessa totalidade, onde o sentido da história vinha inscrito na relação de reciprocidade entre parte e todo no interior da forma literária, era um aspecto central da comparação que Jolles pretendia estabelecer entre a forma memorável e a imagem de Huizinga — e, vale adiantar, a divergência que ficará mais clara na oposição de Huizinga, em sua "tréplica", ao que entendia como uma redução da atividade historiadora à sua dimensão textual.

O historiador construía o seu relato com fatos "puramente históricos", mas diante da exigência de elaborar uma ordem de sentido, ele atualizaria os esquemas formais próprios à disposição do espírito para o factual, configurando uma "totalidade" a partir da enunciação de uma série de pormenores históricos que, apesar de não terem necessariamente uma relação explicativa ou causal direta com o evento principal a ser relatado, eram constantemente opostos, comparados, comentados, interpretados e finalmente relacionados uns aos outros até formar "isso que pode ser definido como o "ponto culminante" [pointe] da história, o seu sentido profundo". "Com a composiçáo de uma forma literária, o evento relatado pelo historiador sairia da "dimensão histórica apresentada" para produzir o que Jolles chamaria em Formas simples de "efetividade vinculada", referindo-se à totalidade coerente e significativa

acontecimento, diremos que se deu o nascimento de uma Forma Simples." JOLLES, André. Formas simples, op. cit., p. 46.

${ }^{40}$ HUIZINGA, Johan; JOLLES, André. Clio et Melpomène, op. cit., p. 494. "On est en presence d'une disposition mentale qui travaille sur le concret. (...) On voit (...) comment cette disposition mentale s'accorde avec une chaîne de pensées precise, qui crée une forme".

${ }^{41}$ Ibidem, p. 501. "Ces données nous sont arrives dans des forms où l'on cherche à saisir l'objetivité et la réalité. (...) Mais ces fait sont — pour répéter tes mots — 'toujours arbitraries et plus ou moins fortuits', incohérents."

${ }^{42}$ Ibidem, p. 495. "où tous les détails du complexe ont une signification, son rapportés les un aux autres et son remplis de la signification de l'emsemble."

${ }^{43}$ Idem. "ce qu'on peut appeler le 'fin mot' [pointe] de l'histoire, son sens profond." 
que, formada a partir dos dados do passado, existiria apenas no interior do texto historiográfico. ${ }^{44}$ Esse processamento linguístico do concreto seria precisamente o ponto de separação entre o simples "relato" ou "protocolo" de um acontecimento, sua fixação no tempo e no espaço tal como "aconteceu", e o relato histórico [historie] propriamente dito, no qual se atribuía sentido, e direção, ao acontecido por meio da composição de uma forma literária, permitindo, assim, a sua saída de um mero sequenciamento diacrônico para a fundação de uma ordem de sentido em que o todo seria sempre mais que a soma de suas partes.

Sobre a relação entre o relato histórico e a realidade concreta que o historiador relata, Jolles afirmava que o "enquadramento" literário da experiência não significaria um cancelamento da dimensão do concreto, da factualidade, mas apenas que a disposição mental que trabalha sobre o factual produziria uma forma literária para satisfazer as "condiçóes do conjunto", no qual o acontecimento viria organizado e fixado para formar uma "representação do verdadeiro", seu objetivo final.

O escritor de história [geschiedschrijver] não elaborou o histórico [het historische] deliberada e arbitrariamente; nem lhe deu uma forma artística [kunstvorm], mas ele fez um uso espontâneo de uma forma simples. (...) Assim fazendo, ele estava convencido de reportar a "história" [historie]. Com razão? Mesmo aqui, eu não ouso duvidar. A tarefa da historiografia não é aquela de criar a história pela utilização das formas por meio das quais nós a observamos a partir de uma certa disposição mental ${ }^{45}$

Essas considerações sobre a relação fundamental entre o arranjo dos fatos numa forma literária e a cristalização do sentido através da disposição mental "que dá forma às coisas", ${ }^{6}$ abriam a possibilidade de questionar a hipótese apresentada em $A$ santa de Bernard Shaw sobre o pertencimento preferencial, ou até mesmo exclusivo, da figura de Joana d'Arc ao domínio da forma histórica. Se para Huizinga haveria algo no próprio objeto que parecia resistir à sua incorporação a uma forma literária ou dramática, Jolles, por outro lado, argumentava que nada condicionaria a priori a sua representação numa forma particular. Os fatos da vida de Joana d'Arc relatados pela tradição de modo incoerente e fortuito não teriam qualquer importância ou sentido intrínsecos que lhes assegurasse o pertencimento prévio ao domínio do histórico e da forma histórica [historie], mas apenas "uma tendência, a aspiração a se recompor num sentido ou em outro na direção das nossas formas literárias simples" que

\footnotetext{
${ }^{44}$ JOLLES, André. Formas simples, op. cit., p. 176.

${ }^{45}$ HUIZINGA, Johan; JOLLES, André. Clio et Melpomène, op. cit., p. 496. "Le escrivain n’a pas elabore consciemment l'histoire; néanmoins il l'a transformée d'une manière arbitraire pour lui donner une forme litteraire, il a fait um usage spontané d'une forme simples. (...) Ainsi faisant, il était convaincu de rapporter l'histoire'. A juste raison? Même ici, je n'ose pas em douter".

${ }^{46}$ JOLLES, André. Formas simples, op. cit., p. 222.
} 
seriam "o lugar onde o universo pode se realizar de maneira determinada" ${ }^{47}$ Além da forma do memorável, a história de Joana d'Arc poderia ser apresentada segundo outras duas possibilidades: na forma do "Mito", a preferida de Jolles, cuja disposição espiritual materializava o desejo de saber sobre a origem e o significado de um fenômeno, e como "Legenda", a forma adotada pela Igreja Católica para disponibilizar a história da personagem francesa para a imitatio da vida santa.

Cada uma dessas intençôes comunicativas, para o factual, o saber ou a imitatio, faria com que o mesmo fato — destituído, em si mesmo, de importância intrínseca — fosse integrado de acordo com os gestos verbais de uma ou outra forma simples, representando-o a cada vez de maneira distinta: o trabalho da linguagem selecionava, no plano dos acontecimentos, aqueles que encerram o sentido que a disposição espiritual quer imprimir. "Assim que nossa disposição espiritual nos empurra para uma forma literária, essa forma incorpora esses dados a sua própria maneira." ${ }^{38}$ Esse seria o caso, por exemplo, de como se interpretava o fato de que Joana d'Arc não despertaria desejo carnal em seus companheiros de batalha. Do ponto de vista do memorável, este dado permitiria vislumbrar o contraste entre a figura da donzela e a tarefa "masculina" a que ela havia se proposto; na legenda, a ausência de desejo se transformava em prova de sua santidade; enquanto no mito a sua pretensa androgenia, "nem homem nem mulher", a colocava na posição de um "ser salvador".

Jolles, em sua carta, dizia concordar Huizinga sobre a inexistência de uma forma artística literária capaz de exprimir a significação completa da história de Joana d'Arc: "talvez você tenha razão de acreditar que, quando a 'história' fala assim tão claramente, a 'poesia' deve se calar". ${ }^{49}$ Essa intervenção acenava para a formulação de Michelet, quando o historiador francês advertia sobre os perigos de "romancear" a heroína francesa, afirmando que a sua "terrível e comovente realidade" desaconselharia uma elaboração literária do tema. "A poesia irá sempre se abster. Pois o que ela poderia acrescentar?" A intenção de "simplesmente dizer as coisas" que Michelet afirmava ter regulado o seu relato sobre Joana d'Arc, para Jolles, seria elaborada a partir da semântica das formas simples, como o espaço linguístico no qual a realidade seria apreendida e se "manifestaria" como história, num processo mediado pela composição de uma forma literária que simultaneamente remetia ao "real" passado e lhe superava ao torná-lo inteligível na representação. "Eu gostaria, da minha parte, de perguntar se a 'história' [historie] mesma não é um poeta [dicther] que não conhece, de fato, nenhuma forma artística [kunstvorm], mas não pode passar sem as formas simples." 50

\footnotetext{
${ }^{47}$ Ibidem, p. 175.

${ }^{48}$ HUIZINGA, Johan; JOLLES, André. Clio et Melpomène, op. cit., p. 501. "dès que notre disposition mentale nous a pousses à une forme littéraire, cette forme incorpore chaque fois ces données à son propre manière."

${ }^{49}$ Ibidem, p. 502. "Peut-être as-tu raison de croire que, quand l'histoire' parle si clairement, la 'poésie' doit se taire."

${ }^{50}$ Idem. "Je voudrais pour ma part savoir si "histoire' même n'est pas une sorte de 'poésie', qui ne connaît vraiment aucune forme littéraire, mais qui ne peut pas passer de formes simples."
} 
Destarte, a sugestão de que a história como "representação do verdadeiro" assumia os contornos de uma forma simples tornaria possível observar a historiografia de um ponto de vista diferente, para além da simples oposição — ou até mesmo da clássica hierarquização aristotélica, evocada por Huizinga em seu artigo — entre História e Literatura. Ao apontar para como a história se constituía como forma literária através das mesmas condiçóes estruturais que estavam na base de toda produção no âmbito da literatura - como locus de atualização de uma disposição do espírito numa produção linguística —, Jolles inscrevia a atividade historiadora no domínio do ato poético da linguagem que cria formas [Gestalten] para apreender, significar e representar o universo da experiência humana e, desse modo, oferecer uma imagem "textual” da realidade.

Em sua carta a Huizinga, Jolles reapresentava a questão da imaginação numa chave em que o "elemento estético da representação histórica" — o que a história e arte teriam em comum segundo as reflexôes huizinguianas — aparecia vinculado ao domínio das formas simples. O caráter estético da operação histórica estaria, segundo ele, no uso espontâneo feito pelo historiador do repertório das formas simples que conformava a "realidade" histórica a partir de a priori expressivos, emoldurando o mundo da experiência numa rede de sentidos produzidos na linguagem e pela linguagem. "Tentei esclarecer isso que você chama aqui de 'corresponder' quando escrevi que no memorável os fatos (...) são ordenados de maneira tal que a importância de cada detalhe singular aumenta até constituir um conjunto dotado de sentido" ${ }^{1}$ Assim como a imagem histórica de Huizinga não era uma reprodução do passado, mas uma representação capaz de criar inteligibilidade a partir dos critérios de seleção e interpretação, a forma simples do memorável, entendida como ato poético da linguagem que transforma o efetivo em História, não produziria uma cópia do real, mas um sentido de ordem superior que remetia de maneira simbólica aos dados da experiência. Desse modo, a História como elaboração formal da tradição deveria ser compreendida como uma espécie de operação linguístico-literária em que a disposição espiritual para o efetivo se atualizava na forma literária do memorável e, por essa via, transmutava o universo factual em imagens textuais do passado.

\section{$\mathrm{O}$ armazém de Clio}

A resposta de Huizinga à carta de Jolles, bastante breve, concentrava-se numa espécie de esclarecimento sobre o que fora sua intenção ao tratar do "sentido histórico" e da formação das imagens históricas em seu texto sobre Bernard Shaw. Em um primeiro momento,

\footnotetext{
${ }^{51}$ Ibidem, p. 501. "J'ai cherché à éclaircir ce que tu appelles ici 'correspondre' quand j'ai écrit que dans le mémorable les faits (...) sont ordenées d'une manière où l'importance de chaque point particulier est augmentée, jusq'à former un esemble significatif."
} 
ele afirmava "concordar perfeitamente" com Jolles que o historiador reagrupava os fatos de uma maneira que os "carregava" de uma significação mais alta ao ligar-lhes uns aos outros dentro de um "todo significativo e coerente". Afinal, qualquer livro sobre teoria da História reconheceria que toda "representação histórica de um conjunto de fenômenos, mesmo a mais árida e documentária, repousa sobre uma escolha consciente e sobre a interpretação do material" ${ }^{52}$ Contudo, com seu argumento a respeito da coincidência entre a forma histórica e o "memorável", Jolles não teria conseguido provar que a representação histórica, ao fazer esse arranjo dos dados da tradiçáo, seria "uma forma literária em si mesma".

Embora concordasse que a intencionalidade historiadora se fundamentava num exercício de atribuiçẫo de forma ao conteúdo da experiência histórica, expresso na operação de construir formas inteligíveis do real, Huizinga náo via nessa relação um motivo para dissolver a distinção entre Clio e Melpomene, colocando a História sob o signo de um artifício literário. Mais do que simplesmente uma "arte" - uma "velha palavra" que, segundo afirmava em sua aula de 1905, "ameaçava tornar-se demasiada estreita" para dar conta da complexidade das funçôes mentais nas quais ela tem origem ${ }^{53}$ - a literatura deveria ser pensada como uma "composição (que palavra excelente!), uma função primordial do espírito".${ }^{54}$ Assim, ao sustentar que toda comunicação de um fato assumia uma forma precisa, "que se pode definir como "literária", Jolles teria demonstrado apenas que a expressão literária era uma "forma superior de sintaxe", inevitável e indispensável a toda comunicação linguística de sentido, mas compartilhada de maneira distinta pela História e a Literatura.

Em sua resposta, Huizinga ainda esclarecia que o conceito de "sentido histórico" apresentado em seu artigo sobre Bernard Shaw não se referia à dimensão textual, descritiva, do ofício do historiador, mas à "percepção" do passado. "Quando eu penso na representação histórica (...), não penso, em primeiro lugar, em uma descrição precisa, mas antes em uma imagem indefinida, mutável, aqui vaga e ali intensa, que vive na consciência de uma geração". ${ }^{5}$ Com essa retificação, Huizinga parecia sugerir que a pergunta que Jolles havia lançado em sua carta a partir do conceito de "sentido histórico" — o que aconteceria na relação entre o historiador e o passado - não poderia ser esgotada em sua hipótese sobre as formas simples. O problema em observar a realidade histórica do ponto de vista da forma do memorável - isto é, da forma que o relato deve assumir para se constituir como relato histórico - era obscurecer um aspecto decisivo dessa relação, na qual o memorável se aplicaria, "mas não completamente". Ao redirecionar a questão proposta por Jolles, Huizinga indicava

52 Ibidem, p. 504. "représentation historique de un ensemble d'événements, même le plus sèche et documentaire, repose sur um choix conscient e sur l'interprétation de la matière."

${ }^{53}$ HUIZINGA, Johan. El element de las representaciones históricas, op. cit., p. 96.

${ }^{54}$ Id; JOLLES, André. Clio et Melpomène, op. cit., p. 503. "une composition (quel excellent mot!), une function primordiale de l'esprit."

${ }^{55}$ Ibid, p. 504. "Quand je pense à la représentation historique, (...) je ne pense pas d'abord à une description precise, mais plutôt à une image indéfinie, changeante, ici vague et là plus perçante, que vit dans la conscience d'une génération." 
que a relação entre o historiador e o passado seria mediada não pela "composição" literária, mas pela "consciência” histórica em sua dimensão como memória cultural. Refletindo sobre como era possível construir imagens a partir dessa relação, ele defendia não ser necessária a elaboração de uma forma literária, indicando que a noção de imagem assumia, aqui, uma posição anterior à sua cristalização num texto "literário".

Entre a imagem cambiante "que vive na consciência de uma geração" e a "imagem inteligível" que o historiador criava estaria o processo definido por Huizinga nos termos de uma "metamorfose de imagens em outras imagens", ${ }^{56}$ realizada através de um jogo de espelhos no qual a cultura via seu passado refletido no presente, ao mesmo tempo que projetava sobre ele uma "imagem" capaz de provisoriamente capturá-lo como parte de sua própria historicidade. "Em cada mente aquele conhecimento [de um fragmento do passado] não pode nunca ser mais do que uma espécie de memória suscetível de evocar imagens" — diria Huizinga em seu ensaio A tarefa da história da cultura, ${ }^{57}$ publicado pouco tempo depois de Clio e Melpomene. Esse modo de observar a disciplina da História como "órgão da cultura" incorporava a questão do movimento e da descontinuidade da forma histórica, sem chegar, contudo, ao ceticismo que ele via como uma resposta inapropriada ao caráter potencial e relativo do trabalho historiográfico. Nesse sentido, o historiador se revelaria como um curador e um intérprete das imagens ainda vivas da tradição num processo de apropriação e reinvenção que criava imagens sujeitas a metamorfoses incessantes, mas que deveriam ser construídas sempre a partir da ambição historiográfica de narrar "o que realmente aconteceu” — fronteira decisiva que separaria a História de outras formas de compreensão do mundo, como a Literatura.

A distinção entre História e Literatura era central na avaliação de Huizinga sobre o engenhoso exercício proposto por Jolles de compor o relato sobre Joana d'Arc a partir das formas simples do mito, da legenda e do memorável. Ele era categórico em afirmar que a musa Clio não seria tão flexível quanto seu amigo parecia reivindicar. Por mais atraente que fosse conceber a Donzela representada na forma do mito da salvadora, como uma espécie de Atena ou Ushas, não se podia esquecer nem por um momento que Joana d'Arc, ao contrário das deusas míticas, existiu de fato, que ela "esperou, ousou e sofreu". Com essas palavras, Huizinga pareceria indicar que por mais que os fatos históricos fossem elaborados por meio da linguagem a partir de uma "sintaxe superior" literária, os seus limites jaziam numa esfera anterior, ou exterior, à linguagem e sua atualização na literatura.

Ao leitor, que não te conhece, poderia parecer que você entra no armazém de Clio para lhe pedir: Você poderia me mostrar Joana d'Arc nas diversas formas que você tem? E a musa

\footnotetext{
${ }^{56}$ HUIZINGA, Johan. El elemento de las representaciones históricas, op. cit., p. 97.

57 O ensaio A tarefa da história da cultura, publicado em 1929, é uma compilação revisada de duas conferências apresentadas por Huizinga em 1926. HUIZINGA, Johan. Il compito della tarefa della cultura. In: HUIZINGA, Johan. Le immagini della storia. Torino: Giulio Einaudi, 1993, p. 37. "quella conoscenza non può mai essere piú di una sorta di memoria da cui si possono richiamare delle immagini."
} 
responde: claro, eu a tenho como memorável, como legenda e como mito... Clio me observa com um ar severo e me pergunta quase ameaçadora: Você acredita nas coisas que eu posso te oferecer? E eu respondo trêmulo: se não for assim, eu não virei mais diante de você: dá-me o que peço. ${ }^{58}$

Se para Jolles os dados da tradição, em si mesmos "incoerentes", poderiam ser incorporados à maneira da disposição mental que conduz a uma forma literária — encontrando ali "um significado que é a cada vez diferente em relação à forma interessada” — , para Huizinga o conteúdo "factual" dos fatos históricos assinalaria o caráter particular da intencionalidade historiadora que criava imagens a partir de um jogo em que as regras eram engendradas pela resistência que o material da tradição oferecia ao procedimento configurativo da imaginação histórica, tocando, assim, nas diferenças formais entre a narrativa histórica e a narrativa literária. Essa distinção estava refletida em sua resposta negativa diante da proposta de Jolles de abordar a forma histórica como uma variação da forma literária. No final de sua carta, Huizinga advertia diretamente o amigo sobre as implicaçóes céticas de suas formulaçóes: "Não fale no espírito de uma geração littéralisée que não se importa mais com a verdade factual. Reconheça comigo (eu sei que você o fará) a disposição espiritual que consiste em querer saber como as coisas realmente aconteceram". ${ }^{59}$

Em $A$ tarefa da história da cultura, Huizinga, assim como Jolles, afirmava que a ocupação do historiador seria a de atribuir forma aos materiais da experiência passada a partir de uma "disposição do espírito" particular, o que o fazia caracterizar a sua compreensão da História como vormgeving [dar forma]. Todo trabalho de história "predispóe as relaçôes, desenvolve as formas mediante as quais a realidade histórica pode ser compreendida. A história produz a consciência de compreender ordenando os fatos de modo que eles assumam um sentido". ${ }^{60}$ Por essa razão, a sua verdade nunca poderia ser aquela da mera correspondência, mas uma verdade interpretativa contida na forma por meio da qual se apreendia o "sentido e a coerência" de uma totalidade fundada, por sua vez, pela forma. No entanto, para que esta forma atendesse o imperativo historiográfico da construção de uma imagem "autêntica" do passado, ela deveria se adequar a uma instância que era exterior e irredutível ao exercício

\footnotetext{
${ }^{58}$ HUIZINGA, Johan; JOLLES, André. Clio et Melpomène, op. cit., p. 504. "Au lecteur, qui ne te connaît pas, il pourrait sembler que tu entres dans le magasin de Clio pour le questioner: Veuillez me montrer Jeanne d'Arc dans le diverses forms. Et la Muse répond: Bien sûr, je l'ai comme mémorable, comme légende et comme mythe... Clio me regarde d'un air sévère et me demande presque menaçante: Croyez-vous dans les choses que je peux vous offrir? Et je réponds em tremblant: Si je ne le faisais pas, je ne viendrais pas auprès de vous: donnez-les-moi."

${ }^{59}$ Ibidem, p. 505. "Ne parle donc pas dans l'esprit d'une generation 'litterarisée', qui n'a pas de souci pour la vérité factuelle. Reconnais plutôt avec moi (je sais que tu feras ainsi) la disposition mentale qui consiste à vouloir savoir comment les choses se sont vraiment passées.”

${ }^{60}$ HUIZINGA, Johan. Il compito, op. cit., p. 74. "predispone delle relazioni, svillupa delle forme mediante cui la realtà passata può essere compresa. La storia genera la consapevolezza di comprendere ordinando i fatti in modo tale che essi assumano un senso."
} 
formal do historiador. Essa adequação só poderia ser obtida — afirmava Huizinga a partir de uma frase de Theodor Lessing ${ }^{61}$ apenas aludida por Jolles em sua carta aberta — quando se pensava o ofício do historiador não como um "dar sentido ao que é carente de sentido" [Sinngebung des Sinnlosen], algo que se aproxima da perspectiva de Jolles sobre a pretensa neutralidade dos fatos históricos incorporados à forma literária, mas antes como uma "interpretação de algo que é rico de sentido" [Sinndeutung des Sinnvollen]. Apenas na medida em que "a história é vista como Sinndeutung des Sinnvollen, vale o critério segundo o qual não se pode chamar de história aquilo que não nasce da necessidade de uma imagem absolutamente 'autêntica' de um certo passado". ${ }^{62}$

A insistência para que Jolles reconhecesse a "disposição espiritual" de saber "como as coisas realmente aconteceram" era central para o desenvolvimento da argumentação de Huizinga sobre o caráter objetivo do conhecimento histórico, uma vez que esse impulso ético para o factual e o concreto determinaria de maneira fundamental as fronteiras entre as "formas espirituais" da História e da Literatura. Apesar de reconhecer que, no final das contas, ambas dependiam de uma mesma "forma superior de sintaxe" para criar imagens e, através delas, dar sentido à experiência, a profunda diferença entre o vormgeving histórico e o vormgeving literário estaria na maneira essencialmente diversa de lidar com o seu material. ${ }^{63}$ Ao contrário da História, que estaria sempre constrangida pelas normas que controlavam a autenticidade de sua imagem do passado — indicando um mundo "real" e efetivo para além, ou para fora, da narrativa do historiador - a força do vormgeving literário estava na sua flexibilidade, na liberdade de sua composição e na infinita possibilidade de sugestão.

A pergunta se a pessoa pratica história ou literatura pode receber uma resposta totalmente definitiva testando qual é a disposição mental a partir da qual ela trabalha. No caso em que falta a exigência primária de 'autenticidade' e o desejo profundamente sincero de chegar a descobrir como algo 'realmente aconteceu' (...), ela não está praticando história. ${ }^{64}$

${ }^{61}$ Em sua obra Geschichte als Sinngebungdes Sinnlosen (1919), ao tecer um ataque radical às concepçôes de História do Historicismo, Theodor Lessing considerava com ceticismo a possibilidade de um conhecimento objetivo do passado, argumentando que a atribuição de sentido, forma, causalidade e coerência ao processo histórico dependiam inteiramente do interesse do historiador. "A história se origina nos desejos e volições, necessidades e intençóes, é a realizaçâo das 'visōes sonhadoras' da raça humana... o sentido da história é apenas o sentido que eu mesmo atribuo, e a evolução histórica é um desenvolvimento de mim para mim mesmo". LESSING apud IGGERS, G. The Idea of Progress: a critical reassessment, The American Historical Review, v. 71, n. 1, p. 1-17, 1965.

${ }^{62}$ HUIZINGA, Johan. Il compito della tarefa della cultura, op. cit., p. 64. "la storia viene vista come Sinndeutung des Sinnvollen, vale il critério secondo cui non può chiamarsi storia ciò che non nasce dal bisogno di um'immagine assolutamente 'autentica' di um certo passato."

${ }^{63}$ OTTERSPEER, Willen. Reading Huizinga. Amsterdã: Amsterdam University Press, 2010, p. 174.

${ }^{64}$ HUIZINGA, Johan. Il compito della tarefa della cultura, op. cit., p. 61. "La domanda se una persona pratichi storia o letteratura può ricevere uma risposta senza dubbio definitiva se si va a verificare qual è la preoccupazione mentale da cui il lavoro di quella persona muove. Nel caso in cui manchi l'esigenza primaria di 'autenticità' e il desiderio profondamente sentito di arrivare a scoprire con quanta certeza qualcosa 'è accaduto veramente' (...), non si sta praticando della storia." 
À argumentação do "morfólogo que se ocupa de História da Literatura" — assim Jolles havia se definido na carta ao amigo - e que atribuía à "forma" o valor de uma hipótese sobre a especificidade da História, Huizinga opunha a dificuldade de garantir o contato "límpido e imediato" com o passado que Jolles acreditava ver refletido na forma do memorável. ${ }^{65}$ A escrita da História que na morfologia das formas simples vinha apresentada como o resultado de um movimento que seguia da tradição para o relato — ou do "texto" da tradiçáo para o "texto" do historiador - apresentava-se, para Huizinga, como o produto de uma mediaçáo complexa entre o presente e o passado de uma cultura. Se para Jolles a operaçáo da escrita da história aparecia como um trabalho da linguagem sobre a linguagem, num exercício de criar a inteligibilidade dos acontecimentos através da forma em que o relato histórico se condensava, para Huizinga essa operação dizia respeito a um espelhamento complexo que atualizava o passado ausente por meio da evocação de imagens, de uma forma histórica que, apesar de ser construída pelo historiador, deveria reconhecer o pertencimento do passado a uma trama de sentidos atribuídos pela cultura.

\section{As faces de Clio}

A correspondência entre Jolles e Huizinga sobre o tema da escrita da História é um momento importante da relação entre os dois que revela um percurso intelectual trilhado em paralelo em que o problema da forma, suas potencialidades e suas tensóes para observar a multiplicidade do mundo dos fenômenos em termos de uma unidade projetada pelo intérprete, colocava-se como o núcleo de um diálogo feito de aproximaçôes e distanciamentos que marcariam de modo fundamental o desenvolvimento de suas pesquisas histórico-culturais no campo da literatura e da história. A intuição compartilhada por ambos, mesmo que colocada a serviço de projetos distintos - e, como mostra a correspondência, até certo ponto, irreconciliáveis —, era que a forma deveria ser pensada como sendo constitutiva do objeto, como elemento que, ao mesmo tempo, cria este objeto e o representa ao fundar uma realidade "ideal" que sustenta e guia a imagem como síntese final do esforço de apreender, no "fenômeno literário" e na história, o domínio da factualidade. ${ }^{66}$ Embora dirigissem a atenção para o mesmo conjunto de questôes e empregassem um vocabulário conceitual construído em torno do "problema da forma", uma divergência fundamental os separava na apreciação da prosa historiográfica. Se para Jolles a imagem como síntese da representaçáo sugeria o problema de chegar a saber o que acontece entre o historiador e o passado, revelando uma gramática própria a essa relação que inscreve a forma histórica no impulso de cons-

\footnotetext{
${ }^{65}$ CONTARINI, Silvia. Gli asfodeli della storia. A proposito della 'Corrispondenza' di Johan Huizinga, Intersezioni, v. XI, n. 1, p. 161-168, 1991. p. 164.

${ }^{66}$ Ibidem, p. 162.
} 
truir sentido linguisticamente através de formas simples anônimas, coletivas e impessoais, Huizinga, por outro lado, se interrogava sobre como o historiador poderia construir uma imagem "autêntica" do passado.

Apesar de a insistência em saber "como as coisas realmente aconteceram" sugerir uma aproximação de Huizinga a um certo realismo ingênuo - expresso, por exemplo, no emprego constante da máxima de Leopold von Ranke - é preciso reconhecer, entretanto, que seu anseio por acessar a "realidade" passada foi concebido de um modo muito mais complexo e elusivo. Sua crítica ao realismo histórico, constante ao longo de toda a sua obra como historiador, indica um afastamento decisivo da ideia do passado como uma entidade completamente autônoma ao processo de atribuição de sentido que se articula em torno da ambição de "dizer o real”, reconhecendo, assim, o caráter paradoxal do impulso em direção a um passado constituído sob o signo da perda, como objeto ausente irredutível a todo esforço de elaboração.

Em uma imagem sugestiva da musa Clio, Huizinga dizia vê-la "tranquila e séria" recolhendo "os asfódelos no país das sombras". ${ }^{67}$ A simbologia dos asfódelos — flores das ruínas e dos cemitérios, que na mitologia grega recobrem os campos de Hades — sugeria sua lida com os mortos, com um passado que apenas deixava para trás rastros e indícios, e sua tarefa de lembrança, de recolher as flores que subjazem sobre as ruínas do passado, dando-lhes a forma de uma narrativa que recorda ao evocar imagens de vidas extintas. Nessa figuração de Clio, a musa parece oscilar entre a consciência da perda, da ausência do passado, e o esforço de tecer lembranças que, sempre fugidias, ligavam o presente e o passado num ofício que se constituía por meio da imaginação dirigida para a metamorfose de imagens retidas pela memória na “imagem teórica a que chamamos História”. Para isso, os predicados de Melpomene, artífice de cores e figuras que usa das palavras para conjurar a realidade em imagens e cenas, colocavam-se a serviço da tarefa de Clio de narrar "o que realmente aconteceu" por meio de uma evocação de imagens concretas do passado. Assim, Clio e Melpomene convergiam para formar a dialética sem síntese que constituía o conhecimento histórico como saber potencial, como "ciência inexata par excellence". ${ }^{68}$

Mas se para Huizinga o reconhecimento da proximidade fundamental entre Clio e Melpomene não implicava a dissolução de uma na outra por conta do imperativo de verdade próprio à forma histórica, para Jolles, a construção de uma fronteira entre as musas ocultaria a presença de uma operação comum que ligava a escrita da história ao domínio do "fenômeno literário". Em sua carta de 1925, assim como em Formas simples anos depois, Jolles insistia no potencial de uma reflexão sobre a escrita da História que a tomava por aquilo que ela sempre fora para além das suas diversas atualizaçôes ao longo do tempo, ou seja, um exercício de elaboração do mundo histórico através da linguagem. Dessa perspectiva,

\footnotetext{
${ }^{67}$ HUIZINGA, Johan. La scienza storica. Roma: Editori Laterza, 1979, p. 99.

${ }^{68}$ Ibidem, p. 56.
} 
a composição do texto historiográfico deveria ser observada como uma composição literária engendrada por uma operação linguística que, partindo da disposição espiritual para o concreto, dava origem à forma capaz de transformar o "efetivo" em História, o memorável.

Referindo-se à insistência de Huizinga sobre a necessidade de distinguir uma disposição mental que contemplasse a expectativa de "verdade" na História, Jolles respondia numa carta privada de 1928: “'A disposição espiritual que consiste em querer saber como as coisas aconteceram realmente (...)?’ Eu gostaria antes de saber o que são as coisas realmente." ${ }^{6}$ Fora das limitaçôes de uma abordagem fundada sobre o caráter individual dos fenômenos, sua manifestação única e diacronicamente delimitada, o que se queria chegar a conhecer na morfologia jollesiana eram as condições de possibilidade das "coisas", a configuração formal que, preservada num "núcleo originário", atualiza-se no espaço contingente da história. Para isso, no caso da escrita historiográfica, Jolles dissolvia as fronteiras entre as musas Clio e Melpomene no sentido de incorporar a História ao território da literatura, ao ato poético que constitui a linguagem como poesia "sem a intervenção — por assim dizer, de um poeta".

As posiçóes divergentes de Jolles e Huizinga sobre o tema da escrita da História, mais do que trincheiras em uma guerra entre partidos opostos, apontam para o esforço compartilhado de compreender a empresa historiográfica em sua complexa tarefa de interpretar e dar a ver o passado. Suas contribuiçôes permitem incluí-los dentro de um longo debate sobre a relação entre forma e conteúdo, entre a representação e o passado, na atividade historiadora, fundada no paradoxo que constitui a História como impulso intelectual para apreender um objeto “ausente". Nesses debates, as duas musas, Clio e Melpomene, são continuamente colocadas em diálogo numa discussão que, apesar de se renovar a todo o momento, parece nunca poder prescindir da reflexão sobre as fronteiras e as aproximaçóes da História com a Poesia, indicando a tensão, continuamente ressignificada, entre a realidade e a linguagem, entre o passado enquanto vivência e o passado como fabricação.

\section{Referência bibliográficas}

ARISTÓTELES. Poética. São Paulo: Editora 34, 2015.

CONTARINI, Silvia. Gli asfodeli della storia. A propósito della 'Corrispondenza' di Johan Huizinga, Intersezioni, v. XI, n. 1, p. 161-168, 1991.

. Introduzione. In: JOLLES, André. I Travestimenti della letteratura. Saggi critici e teorici (1897-1932). Milão: Bruno Mondadori, 2003.

\footnotetext{
${ }^{69}$ JOLLES apud CONTARINI, Silvia. Présentation. In: HUIZINGA, Johan; JOLLES, André. Clio et Melpomène, op. cit., p. 489. "'La disposition mentale qui consiste à vouloir savoir comment les choses se sont vraiment passées...? Moi, je voudrais plutôt savoir ce que les choses sont vraiment.”
} 
. Présentation. In: HUIZINGA, Johan; JOLLES, André. Poetique, n. 100, p. 487505, 1994.

HALLIWELL, Stephen. Introduction. In: ARISTOTLE. Poetics. Cambridge: Harvard University Press, 1955.

. The Asthetics of Mimesis: Ancient Texts and Modern Problems. Princeton: Princeton University Press, 2002.

HUIZINGA, J. Bernard Shaw's Saint. In: Men and Ideas: History, the Middle Ages, the Renaissance. Nova York: Meridian Books, Inc., 1959.

. El elemento estético de las representaciones históricas. Prismas: Revista de Historia Intelectual, n. 9, p. 91-107, 2005.

. Il compito della storia della cultura. In: Le immagini della storia. Turim: Giulio Einaudi, 1993.

. La scienza storica. Roma: Editori Laterza, 1979.

. My path to history. In: Dutch Civilization in the Seventeenth Century and Other Essays. Londres: Collins, 1968.

JOLLES, André. Formas simples. São Paulo: Cultrix, 1976.

. I Travestimenti della letteratura. Saggi critici e teorici (1897-1932). Milão: Bruno Mondadori, 2003.

JOLLES, André; HUIZINGA, Johan. Clio et Melpomène, Poetique, n. 100, p. 487-505, 1994. p. 502.

LANGBEHN, Regula R. La Teoria de las "formas simples" de André Jolles (1874-1946): una reconsideración, Hispanic Research Journal, v. 3, n.3, p. 243-260, 2002.

MICHELET, Jules. Oeuvres complètes. Paris: Flammarion, 1893.

OTTERSPEER, Willen. Reading Huizinga. Amsterdã: Amsterdam University Press, 2010. PASERO, Nicollò. Del buon uso della morfologia. Glosse a Warburg, Curtius e Jolles, Moderna, v. VI, n. 2, p. 35-38, 2004.

PETITIER, Paule. Michelet e a História-ressurreição. Olho d'água, v. 5, n. 2, p. 63-78, 2013.

SCHOLES, Robert. Structuralism in Literature: an Introduction. New Haven \& Londres: Yale University Press, 1974.

SHAW, Bernard. Saint Joan: a chronicle play in six scenes and an epilogue. Londres: London GroupLimited, 1970.

VOOGD, Christophe Nicolaas. Le miroir de la France: Johan Huizinga et les historiens français. Tese (Doutorado) — Universidade de Leiden, 2013. 